\section{Tobacco and epidemiology in Korea: old tricks, new answers?}

\author{
Alex Broadbent, ${ }^{1}$ Seung-sik Hwang ${ }^{2}$
}

The National Health Insurance Service (NHIS) of Korea provides health insurance for over $90 \%$ of the population. The prevalence of smoking among Korean men is one of the highest in developed countries, and cancer incidence and mortality rates are the highest among all Asian countries. ${ }^{1}$ The NHIS has taken legal action against Korean and international tobacco companies and recently suffered a blow at the Supreme Court. ${ }^{2}$ This has attracted comment in Korean epidemiology journals. ${ }^{3} 4$ The familiarity of the issues from the history of epidemiology in Europe and America make the case disturbing and deserving of international attention. In particular, three aspects of the judgement (all identified as problematic in ref. ${ }^{4}$ ) deserve emphasis.

First, tobacco companies successfully argued that, beyond statutory warning labels, they had no duty to warn smokers of the dangers of smoking. Legislation obliges manufacturers to place specific warnings on packets, but the question concerned whether the statutory labels satisfied a duty to warn of the dangers of smoking. The court found no further duty, on the basis that the dangers of smoking are already widely known.

Even if the dangers of smoking are better known than they used to be, it is hard to accept that education is sufficient in this regard, especially given the relation between age of starting smoking, difficulty of stopping, duration of smoking habit, and risk of smoking-related diseases. Moreover, even if the present notoriety of smoking is deemed sufficient, it is largely because of the efforts of epidemiologists and others involved in public health. The Korean Supreme Court's decision implies that the efforts of epidemiologists and others involved in public health to raise awareness of the dangers of smoking have relieved tobacco companies operating in Korea of the cost of doing so, thus

\footnotetext{
${ }^{1}$ Department of Philosophy, University of Johannesburg, Auckland Park, Gauteng, South Africa; ${ }^{2}$ Department of Social and Preventive Medicine, Inha University School of Medicine, Incheon, South Korea

Correspondence to Professor Alex Broadbent, Department of Philosophy, University of Johannesburg, P.O. Box 524, Auckland Park, Gauteng 2006, South
} Africa; abbroadbent@uj.ac.za effectively improving the profitability of selling cigarettes in Korea. The idea that an epidemiologist who has worked hard to raise awareness of the dangers of smoking has thereby helped relieve a tobacco company of a duty to warn is troubling, from the perspective of the profession.

The second troubling feature of the judgement concerns a distinction between specific and non-specific diseases. The Korean Supreme Court has been convinced that diseases come in two kinds, specific and non-specific, with a specific disease being one with a characteristic cause, and a non-specific disease arising from more than one constellation of causes (for more detail on this distinction, see ref. $\left.{ }^{4}\right)$. The idea is that, because smoking is nonspecific, a plaintiff needs to show that it was smoking and not something else that caused the lung cancer.

The distinction between specific and non-specific diseases does not bear the weight that this judgement places on it. All diseases arise from a constellation of factors. ${ }^{5}$ Some diseases have necessary causes such that, without the cause, it would be a different disease $^{6}{ }^{7}$ : for example, diarrhoea without Vibrio cholerae is not cholera. Such diseases would presumably count as 'specific' in the Court's categorisation. However, this feature does not have the overriding significance for causal inference that the Court seems to attribute. If one sees a case of diarrhoea with $V$. cholerae present, then indeed one can make an inference that the $V$. cholerae is causing the diarrhoea; but it remains possible that another cause is present. So even in the case of a so-called specific disease, one needs to show that the cause in question and not something else is causing the disease. This might be easier to do for a specific disease, but for some non-specific disease such as smoking, where the relative risks are very high, it might also be relatively easy to make a compelling case, based on the statistical rarity of lung cancer among non-smokers. The crucial point is that the underlying inference is non-deductive in character in the imaginary cholera case as in the smoking case. Thus, the distinction simply does not have the significance that the Court places on it.
The third troubling feature of the case is an apparent resistance to acknowledging any link between epidemiological evidence and the individual case. This resistance is not unique to Korean law. There is substantial jurisprudential literature on the difficulties of using statistical evidence to prove claims about individuals, ${ }^{8-12}$ and this is because this use of statistical evidence raises foundational issues both in jurisprudence and epistemology. Nonetheless, it is troubling that the situation around the relevance of epidemiological evidence to proof of specific causation remains so poorly understood, given that the use of statistical evidence in other areas, such as forensics, is now commonplace and even a necessity. It is possible to clarify at least the epistemic significance of statistical evidence in the epidemiological case in the following way.

Suppose, hypothetically, that the relative risk of lung cancer among a certain subgroup of male smokers (say, 20 or more per day for 30 or more years) in a certain population is 20, compared with neversmokers. Then the excess fraction of lung cancer among these smokers is $1-(1 / 20)=19 / 20$ or 0.95 . Let us assume that, after carefully considering a wide range of evidence, we make a causal inference, and conclude that this excess fraction is caused by the differences in smoking habits between the two groups.

Now suppose that we take a randomly selected smoker from our group. Assuming that no other evidence is available that might bear on this individual's probability of developing lung cancer without smoking, what is the probability that this randomly selected smoker would have developed lung cancer had he been in the control group? This is the probability of picking a smoker who would not have been part of the excess fraction of $95 \%$; thus, it is $5 \%$.

This does not immediately tell us how smoking is probably causal in a given randomly selected case. Aetiological fraction may exceed excess fraction ${ }^{13}$ : smoking may be a contributory factor in the development of lung cancer, even among those who would have developed it anyway. Since causes can contribute to effects that would have happened anyway, while epidemiological evidence tracks only net differences between groups, we cannot use epidemiological evidence to give us an equation for the probability of causation.

However, assuming that the net difference between the two groups is caused by the exposure, we know that the exposure is causal in at least that many casesperhaps more (because aetiological fraction may exceed excess fraction), but not 
less (or the causal inference would be confounded, contra our assumption). In that case, we can devise an inequality: ${ }^{7} 12$

$$
\mathrm{PC} \geq 1-\frac{1}{\mathrm{RR}}
$$

It would be a mistake to treat this as determinative of causation in an individual case. Other kinds of evidence, such as family history, or whether the individual worked in an asbestos factory, may render a population-based estimate less relevant. Moreover, since this is an inequality, this formula cannot be used to establish a threshold level for the admissibility of epidemiological evidence in relation to causation.

These caveats are important and mean that caution must be exercised in applying population-level epidemiological evidence to individual cases. Nonetheless, it is a myth that epidemiological evidence is totally silent on causation in the individual case. Epidemiological evidence does yield probabilistic conclusions about individuals, if certain assumptions are satisfied, ${ }^{12}$ and arriving at probabilistic conclusions about individuals when certain assumptions are satisfied is part of what law courts do. It is unfortunate that unclear thinking about the relation between epidemiological evidence and specific causation persists in legal contexts.

In summary, it is troubling that tobacco companies are successfully using strategies in Korea which have been tried and found wanting in other jurisdictions. The issue of the duty to warn appears to be an old trick which probably would not work in many other jurisdictions. The other two issues, of specific/non-specific diseases and of epidemiological evidence in proof of individual causation, amount to a different old trick: that of linking a defence to foundational, even philosophical, issues, which therefore cannot be decisively resolved. One name for this trick is obfuscation, and a defence that pulls this trick off is difficult to dislodge.

However, regarding both these latter issues (specific/non-specific diseases, and proof of individual causation using

epidemiological evidence), we believe that it is possible to achieve a useful degree of clarification without pretending to solve the foundational issues, and thus to achieve a more satisfactorily reasoned position. A reasoned engagement leads us to conclude that the distinction between specific and non-specific diseases cannot bear the weight placed on it in the Supreme Court's judgement, and also that epidemiological evidence can be used in at least some circumstances to show that individual causation is more probable than not.

These modest conclusions are not complete solutions to the respective underlying theoretical problems, but they are more reasonable and more useful than the stances that the Court was persuaded to take in its judgement. Philosophical argument can obfuscate, but it can also clarify. Perhaps the strategy of limited and reasoned engagement is not strictly a new answer to old tricks. However, there is a newly emergent appreciation of the philosophical foundations of epidemiology, ${ }^{7}$ and the analyses of specific/non-specific diseases and probability of causation here arise from that work.

Twitter Follow Alex Broadbent at @alexbroadbent

Contributors $A B$ provided the conceptual argumentation and undertook the English language drafting. S-sH provided Korea-specific expertise and information on the epidemiology of tobacco in Korea.

Competing interests None declared.

Provenance and peer review Commissioned; externally peer reviewed.

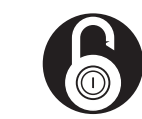

\section{OPEN ACCESS}

Open Access This is an Open Access article distributed in accordance with the Creative Commons Attribution Non Commercial (CC BY-NC 4.0) license, which permits others to distribute, remix, adapt, build upon this work non-commercially, and license their derivative works on different terms, provided the original work is properly cited and the use is noncommercial. See: http://creativecommons.org/licenses/ by-nc/4.0/

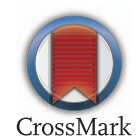

To cite Broadbent A, Hwang S-sik. J Epidemiol Community Health 2016;70:527-528.

Received 2 November 2015

Revised 18 December 2015

Accepted 21 December 2015

Published Online First 14 January 2016

J Epidemiol Community Health 2016;70:527-528. doi:10.1136/jech-2015-206567

\section{REFERENCES}

1 Park S, Jee SH, Shin HR, et al. Attributable fraction of tobacco smoking on cancer using population-based nationwide cancer incidence and mortality data in Korea. BMC Cancer 2014; 14:406.

2 Korean Supreme Court Decision 2011Da22092.

3 Khang $\mathrm{YH}$. The causality between smoking and lung cancer among groups and individuals: addressing issues in tobacco litigation in South Korea. Epidemiol Heal 2015;37:e2015026.

4 Broadbent A. Epidemiological evidence in law: a comment on Supreme Court Decision 2011Da22092, South Korea. Epidemiol Heal 2015;37:e2015025.

5 Rothman KJ. Causes. Am J Epidemiol 1976;104:587-92.

6 Broadbent A. Causation and models of disease in epidemiology. Stud Hist Philos Biol Biomed Sci 2009;40:302-11.

7 Broadbent A. Philosophy of epidemiology. London and New York: Palgrave Macmillan, 2013.

8 Cohen LJ. The probable and the provable. Oxford: Clarendon Press, 1977.

9 Gold S. Causation in toxic torts: burdens of proof, standards of persuasion, and statistical evidence. Yale Law J 1986;96:376-402.

10 Wright R. Causation, responsibility, risk, probability, naked statistics, and proof: pruning the bramble bush by clarifying the concepts. Iowa Law Rev 1988;73:1001-77.

11 Wright R. Liability for possible wrongs: causation, statistical probability, and the burden of proof. Loyola Los Angeles Law Rev 2008;41:1295-344.

12 Broadbent A. Epidemiological evidence in proof of specific causation. Leg Theory 2011;17:237-78.

13 Greenland S, Robins J. Epidemiology, justice, and the probability of causation. Jurimetrics 2000; 40:321. 